\title{
Electrospinning of nanofibers from non-polymeric systems: Electrospun nanofibers from native cyclodextrins
}

\author{
Asli Celebioglu, Tamer Uyar* \\ UNAM-Institute of Materials Science E Nanotechnology, Bilkent University, Ankara 06800, Turkey
}

\section{A R T I C L E I N F O}

\section{Article history:}

Received 7 January 2013

Accepted 7 April 2013

Available online 6 May 2013

\section{Keywords:}

Cyclodextrin

Electrospinning

Nanofiber

\begin{abstract}
A B S T R A C T
Electrospinning of nanofibers from non-polymeric systems is rather challenging, yet in this study, we have successfully performed electrospinning of nanofibers from two of the native cyclodextrins (CDs); $\alpha-C D$ and $\beta-C D$. Electrospinning was carried out for highly concentrated solutions of $\alpha-C D(120 \%$ up to $160 \%, w / v)$ and $\beta-C D(120 \%$ up to $150 \%, w / v)$ in basic aqueous system. At optimal concentration level, the electrospinning of $C D$ solutions yielded bead-free uniform $C D$ nanofibers without using carrier polymeric matrix. Similar to polymeric systems, the electrospinning of CD solutions resulted in different morphologies and average fiber diameters depending on the CD type and CD concentration. The dynamic light scattering (DLS) and rheology measurements were performed in order to examine the electrospinnability of $\mathrm{CD}$ solutions. The existence of $\mathrm{CD}$ aggregates via hydrogen bonding and very high solution viscosity and viscoelastic solid-like behavior of CD solutions were found to be the key factors for obtaining bead-free nanofibers from CDs. The addition of urea disrupted CD aggregates and lowered the viscosity significantly, and therefore, the urea-added CD solutions yielded beaded fibers and/or beads. Although the as-received CDs in powder form are crystalline, the structural analyses by XRD and HR-TEM indicated that electrospun $C D$ nanofibers have amorphous characteristic without showing any particular orientation or crystalline aggregation of $\mathrm{CD}$ molecules.
\end{abstract}

(c) 2013 Elsevier Inc. All rights reserved.

\section{Introduction}

Electrospun nanofibers have received great attention due to their unique properties including extremely high surface area, very light-weight, nano-porous features, and design flexibility for specific physical and chemical functionalizations [1-3]. Unlike other nanofiber fabrication techniques, electrospinning is straightforward, versatile, and very cost-effective for producing nanofibers from variety of materials such as polymers, polymer blends, solgels, emulsions, suspensions, and composite structures [1-7]. Due to their unique properties, electrospun nanofibers and their nanowebs are very promising candidates to be used in various fields such as membranes/filters, biotechnology, textiles, sensors, energy, electronics, and environment [1-3,7-15]. In electrospinning, high molecular weight polymer and high solution concentrations are generally used since entanglements and overlapping between polymer chains play crucial role for producing bead-free and uniform nanofibers [16-18]. For the electrospinnability of solutions, the importance of elasticity and relaxation time rather than molecular entanglements has also been reported [19,20]. The electrospinning of low molecular weight molecules is quite challenging. Yet, few examples have been recently reported about

\footnotetext{
* Corresponding author. Fax: +90 3122664365.

E-mail address: tamer@unam.bilkent.edu.tr (T. Uyar).
}

the electrospinning of non-polymeric systems such as phospholipids [21], diphenylalanine [22], gemini surfactant [23], heteroditopic monomer [24], and chemically modified cyclodextrins [25-29]. Besides solution electrospinning of low molecular weight compounds [21-29], melt electrospinning of small molecules such as 1,3,5-cyclohexane and 1,3,5-benzenetrisamides into fibers was also reported very recently [30]. These studies showed that the key factor for the electrospinnability of these low molecular weight molecules is the self-assembly and self-aggregation of the molecules in their concentrated solutions [21-29] or in their melt state [30]. In short, electrospinning of nanofibers from supramolecular structures is quite interesting and needs further investigation since electrospun supramolecular nanofibers can be used for designing and constructing new advanced functional nanofibrous materials.

Electrospinning of nanofibers from polymers, which usually require organic solvents, is very common; however, electrospinning of nanofibers from renewable resources is always attractive and on demand. Cyclodextrins (CDs) are naturally occurring water-soluble oligosaccharides, and they are produced from the enzymatic conversion of starch. CDs are one of the most studied supramolecular systems, and therefore, electrospinning of nanofibers from CDs would be quite fascinating due to their non-covalent host-guest inclusion complexation capability with other molecules. CDs are cyclic oligosaccharides having a toroid-shaped molecular structure (Fig. 1) which can form intriguing supramolecular structures by 
forming host-guest inclusion complexes (ICs) with variety of molecules [31-33]. The native CDs have either six, seven, or eight glucopyranose units in their molecular structure and are named as $\alpha-C D, \beta-C D$, and $\gamma-C D$, respectively (Fig. 1) [34]. Due to their non-covalent host-guest complexation ability, CDs are quite applicable in various field such as pharmaceuticals, functional foods, cosmetics, home/personal care, textiles, and filtration/separation/ purification systems [31,32,35-37].

CDs can self-assemble and form considerable aggregates via intermolecular hydrogen bonding in their concentrated solutions $[38,39]$. So, this makes it possible for the electrospinning of nanofibers from highly concentrated CD solutions. In fact, in our very recent studies, we have successfully performed electrospinning of nanofibers from three different chemically modified CDs: hydroxypropyl-beta-cyclodextrin (HP $\beta C D$ ), hydroxypropyl-gamma-cyclodextrin (HP $\gamma C D)$, and methyl-beta-cyclodextrin (M $\beta C D)$ [25-27]. The chemically modified CDs have very high solubility when compared to native $\mathrm{CDs}(\alpha-\mathrm{CD}, \beta-\mathrm{CD}$, and $\gamma-\mathrm{CD})$; therefore, the preparation of highly concentrated modified $C D$ solutions in water or polar organic solvents was possible, and the electrospinning of nanofibers from these solutions were successful [25-27]. Following our studies, the electrospinning of nanofibers from HP $\beta C D$ was also reported by two other research groups [28,29]. However, up to date, the electrospinning of native $\mathrm{CD}$ still remains a challenge due to their low solubility when compared to that of chemically modified CDs. Native CDs are soluble in water, yet, their solubility is rather limited due to the presence of intramolecular hydrogen bonding within the $\mathrm{CD}$ molecule, which prevents the formation of hydrogen bond with surrounding water molecules $[38,40]$. Nevertheless, in this study, we were able to obtain highly concentrated homogeneous solutions of $\alpha-C D$ and $\beta-C D$ by using $10 \%(w / v) ~ N a O H$ aqueous solvent system. By using these highly concentrated CD solutions, our efforts on electrospinning of nanofibers from native CDs, $\alpha-C D$ and $\beta-C D$, without using any carrier polymer matrix were quite successful. As anticipated, electrospinning of nanofibers from CDs would be very attractive since nanofibrous materials with unique properties can be produced by combining the very large surface area of nanofibers with specific functionality of the CDs.

\section{Experimental}

\subsection{Materials}

The $\alpha-C D$ and $\beta-C D$ were obtained from Wacker Chemie AG (Germany) commercially. Sodium hydroxide (NaOH) (Fluka, $\geqslant 98 \%$, small beads) was purchased. The de-ionized water was from the Millipore Milli-Q Ultrapure Water System. All the materials were used without any purification.

\subsection{Preparation of $C D$ solutions and electrospinning of $C D$ nanofibers}

The electrospinning of $\mathrm{CD}(\alpha-\mathrm{CD}$ and $\beta-\mathrm{CD})$ solutions was determined according to their solubility limits by trying different solvent types. Electrospinning requires highly concentrated CD solutions; therefore, in order to obtain highly concentrated homogeneous CD solutions, various solvent types including water, $\mathrm{N}, \mathrm{N}$-dimethylformamide (DMF), dimethylacetamide (DMAc), and dimethyl sulfoxide (DMSO) as well as their mixtures were tested, and finally, we were able to get highly concentrated homogeneous $\alpha-\mathrm{CD}$ and $\beta-\mathrm{CD}$ solutions by using $10 \% \mathrm{NaOH}$ aqueous solution. Therefore, $\alpha-C D$ and $\beta-C D$ nanofibers were electrospun from their $10 \% \mathrm{NaOH}$ aqueous solution. The solutions were started to be prepared from $120 \%(\mathrm{w} / \mathrm{v}) \mathrm{CD}$ concentration, and they were increased to the optimized level until the bead-free uniform nanofibers were produced. The homogenous nanofibers of $\alpha$-CD and $\beta-C D$ were obtained at $160 \%$ and $150 \%(\mathrm{w} / \mathrm{v})$ concentrations, respectively. The effect of urea on the fiber formation was investigated by adding $20 \%$ urea ( $w / w$, with respect to $C D$ ) into the optimized concentration of CD solutions. For electrospinning, each CD solution was loaded into a syringe having metallic needle with $0.45 \mathrm{~mm}$ inner diameter, and it was positioned onto the syringe pump (Model: SP 101IZ, WPI) in order to control the flow of the solution. One of the electrodes of the high voltage power supply (Matsusada Precision, AU Series) was clamped to the metal needle tip, and the other was clamped to the grounded cylindrical aluminum collector. The electrospinning parameters were optimized as follows: applied voltage: $15 \mathrm{kV}$, tip-to-collector distance: $10 \mathrm{~cm}$, and the solution flow rate: $1 \mathrm{~mL} / \mathrm{h}$. The electrospinning was performed in a horizontal position in an enclosed Plexiglass box at $25^{\circ} \mathrm{C}$ and $25 \%$ relative humidity conditions.

\subsection{Measurements and characterization}

The rheological properties of the $\mathrm{CD}$ solutions were studied by using rheometer (Anton Paar Physica MCR 301) equipped with cone-plate configuration (spindle type $\mathrm{CP} 40-2$ ). While the shear rate sweep tests were carried out at the range of $0-100 \mathrm{~s}^{-1}$, the frequency sweep oscillatory tests were done at the $0-10 \mathrm{~Hz}$ frequency range. For viscoelastic property measurements, the linear viscoelastic region was determined as $0.01 \%$ strain value. The aggregate size of CD solutions was measured by using Nano-ZS
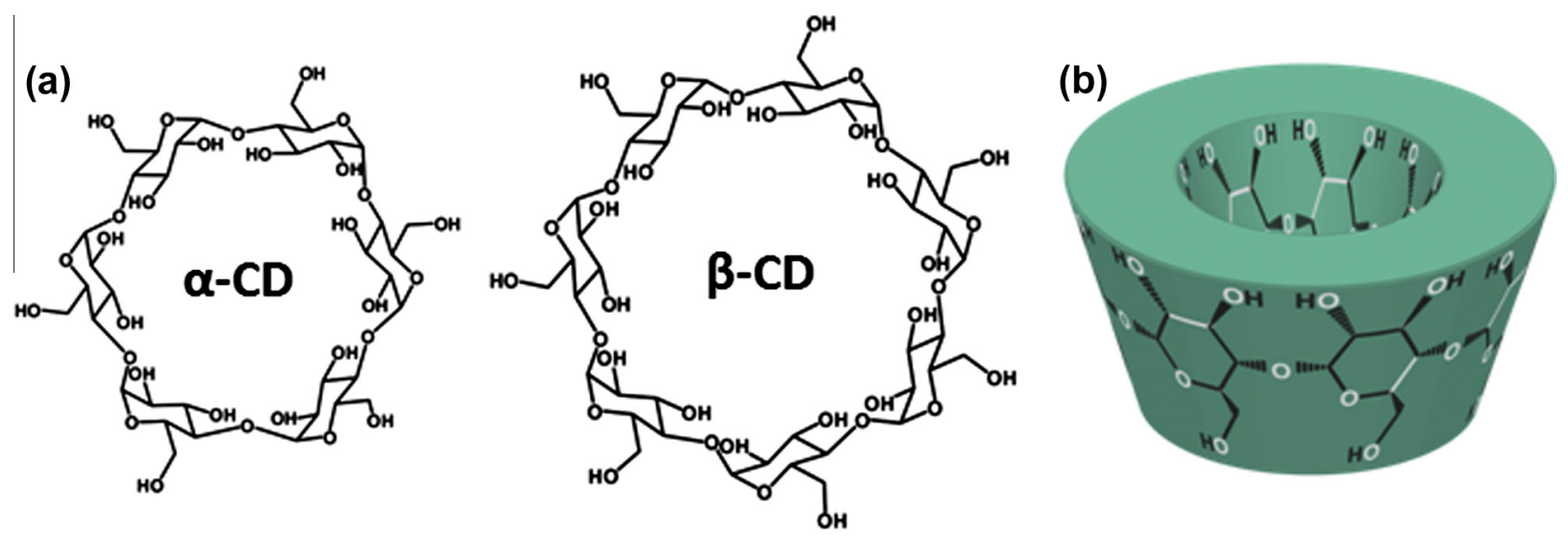

Fig. 1. (a) Chemical structure of $\alpha-C D$ and $\beta-C D$; (b) schematic representation of CD. 
Table 1

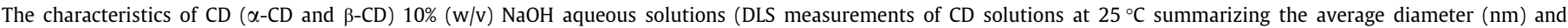
polydispersity index (PDI) of CD aggregates), average fiber diameter, fiber diameter range, and fiber morphology of the electrospun CD nanofibers

\begin{tabular}{|c|c|c|c|c|c|}
\hline Solutions & $\begin{array}{l}\text { Viscosity } \\
\text { (Pa s) }\end{array}$ & $\begin{array}{l}\text { Conductivity } \\
\left(\mathrm{mS} \mathrm{cm}^{-1}\right)\end{array}$ & $\begin{array}{l}\text { Intensity-average diameter/d } \\
(\mathrm{nm}) \text { - PDI }\end{array}$ & $\begin{array}{l}\text { Average fiber diameter (fiber diameter } \\
\text { range) }(\mathrm{nm})\end{array}$ & Fiber morphology \\
\hline $120 \% \alpha-C D$ & 0.16 & 14.33 & $5.50 / 0.55$ & - & Bead structures \\
\hline $130 \% \alpha-C D$ & 0.20 & 11.22 & $6.04 / 0.47$ & - & $\begin{array}{l}\text { Bead structures with few fiber } \\
\text { formation }\end{array}$ \\
\hline $140 \% \alpha-C D$ & 0.26 & 9.06 & $6.38 / 0.40$ & - & $\begin{array}{l}\text { Bead structures with fiber } \\
\text { formation }\end{array}$ \\
\hline $150 \% \alpha-C D$ & 0.32 & 7.42 & $7.30 / 0.70$ & $180 \pm 80(50-560)$ & Beaded nanofibers \\
\hline $160 \% \alpha-C D$ & 0.43 & 5.93 & $8.29 / 0.48$ & $375 \pm 150(80-940)$ & Bead-free nanofibers \\
\hline $\begin{array}{l}160 \% \propto-C D+20 \% \\
\quad \text { urea }\end{array}$ & 0.33 & 4.42 & $6.04 / 0.81$ & - & $\begin{array}{l}\text { Bead structures with few fiber } \\
\text { formation }\end{array}$ \\
\hline $120 \% \beta-C D$ & 0.13 & 12.05 & $4.98 / 0.36$ & - & Bead structures \\
\hline $130 \% \beta-C D$ & 0.16 & 9.77 & $5.14 / 0.53$ & - & $\begin{array}{l}\text { Bead structures with fiber } \\
\text { formation }\end{array}$ \\
\hline $140 \% \beta-C D$ & 0.24 & 8.21 & $5.27 / 0.46$ & $175 \pm 70(90-420)$ & Beaded nanofibers \\
\hline $150 \% \beta-C D$ & 0.33 & 7.25 & $5.96 / 0.43$ & $220 \pm 90(90-460)$ & Bead-free nanofibers \\
\hline $\begin{array}{l}150 \% \beta-C D+20 \% \\
\text { urea }\end{array}$ & 0.15 & 5.53 & $4.91 / 0.92$ & - & Bead structures \\
\hline
\end{tabular}

Zetasizer dynamic light scattering (DLS) system (Malvern Instruments). Before the measurement, the temperature of cell was equilibrated at $25^{\circ} \mathrm{C}$ for $2 \mathrm{~min}$. The conductivity of the $\mathrm{CD}$ solutions was measured with a Multiparameter meter InoLab-Multi 720 (WTW) at room temperature. The scanning electron microscope (SEM) (Quanta 200 FEG, FEI) was used for the morphological characterization of nanofibers. Samples were sputtered with $5 \mathrm{~nm}$ Au/Pd (PECS-682) and the average fiber diameter (AFD) was calculated from the SEM images by analyzing at least 100 fibers. X-ray diffractometer (XRD) (X'Pert powder diffractometer, PANalytical) was used to determine the X-ray diffraction pattern of as-received $\mathrm{CD}$ powders and $\mathrm{CD}$ nanofibers with $\mathrm{Cu} \mathrm{K} \alpha$ radiation in the $2 \theta=5$ $30^{\circ}$ range. Transmission electron microscope (TEM) and high resolution transmission electron microscope (HR-TEM) (FEI - Tecnai G2F30) were also used for the detailed structural characterization of CD nanofibers. For TEM imaging, HC200 TEM grids were attached on the aluminum foil and the samples were collected on the grids.
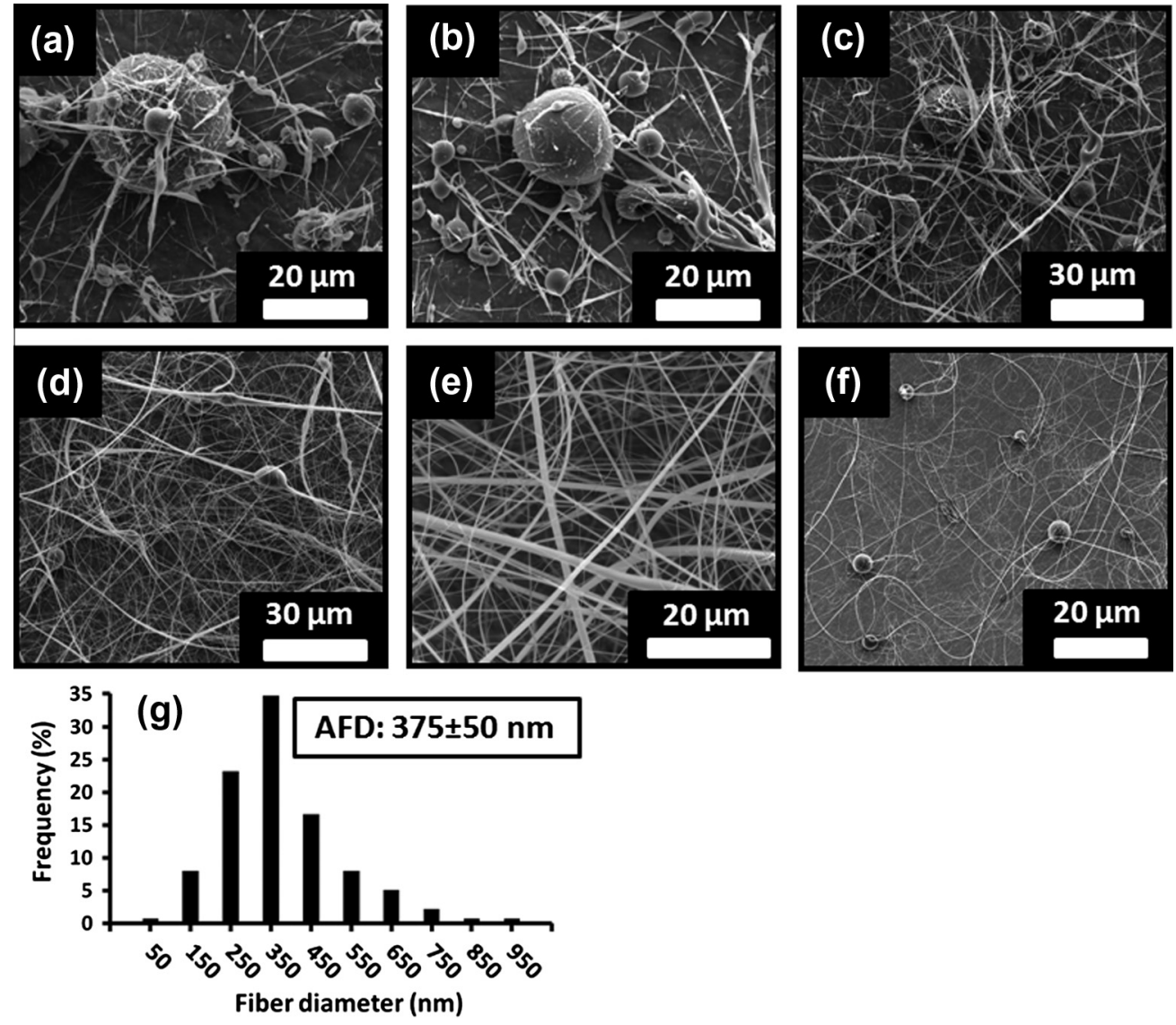

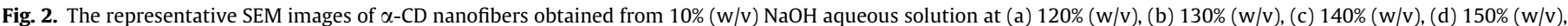

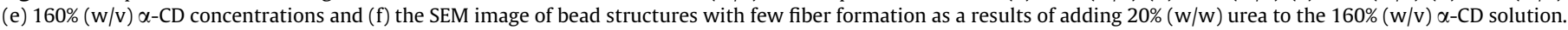
(g) Fiber diameter distribution of electrospun nanofibers produced from $160 \%(w / v) \alpha$-CD concentration. 

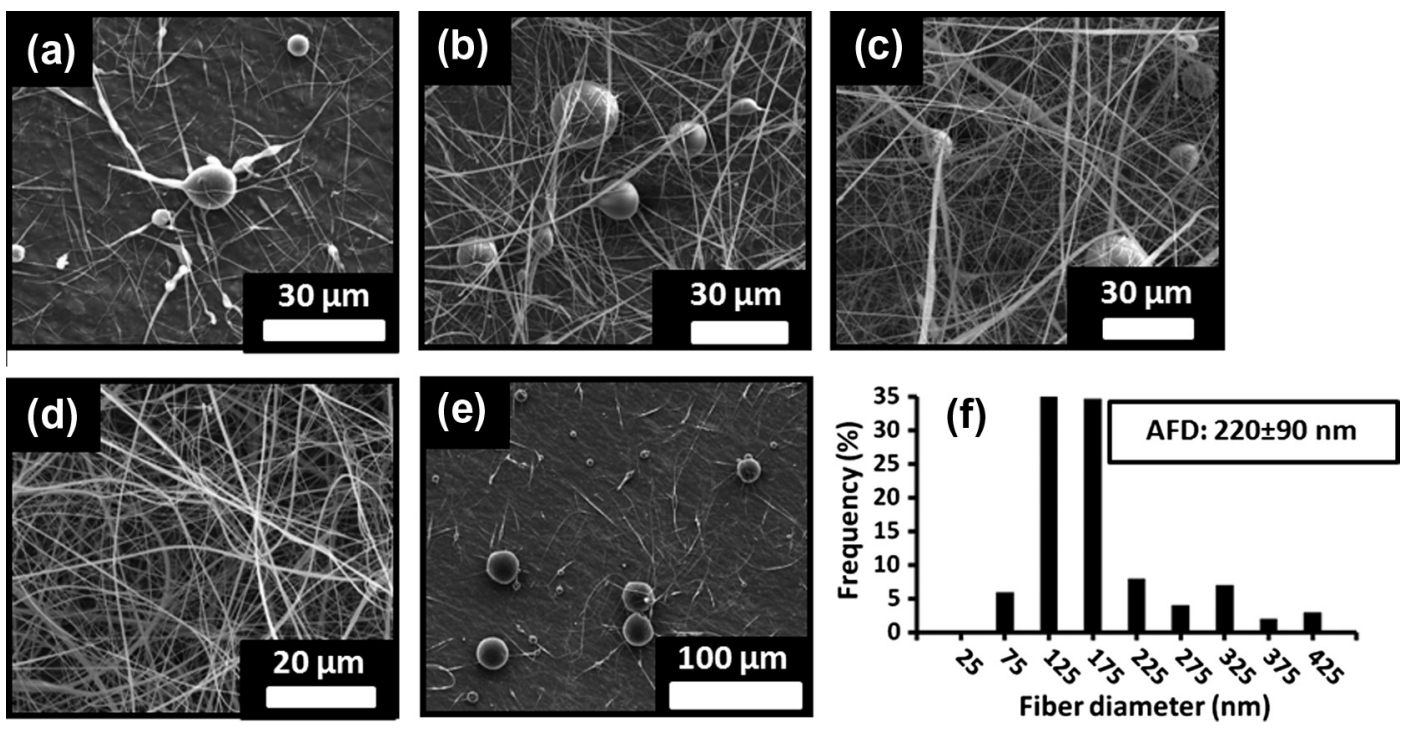

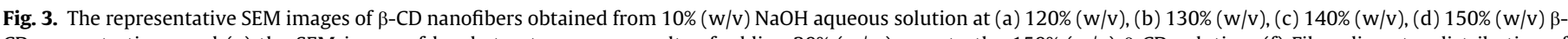

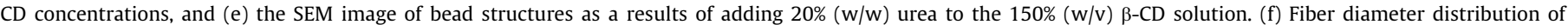
electrospun nanofibers produced from $150 \%(w / v) \beta-C D$ concentration.

\section{Results and discussion}

\subsection{Electrospinning of nanofibers from native cyclodextrins ( $\alpha-C D$ and $\beta-C D)$}

Highly concentrated $\alpha$-CD ( $120 \%$ up to $160 \%, w / v)$ and $\beta-C D$ ( $120 \%$ up to $150 \%, \mathrm{w} / \mathrm{v}$ ) solutions were prepared by dissolving the $\mathrm{CDs}$ in $10 \%(\mathrm{w} / \mathrm{v}) \mathrm{NaOH}$ aqueous solution. The solution preparation, electrospinning parameters/conditions, and the details of the characterization techniques are summarized in the experimental section. The characteristics of the CD solutions, the morphology and the average fiber diameters of the electrospun $C D$ nanofibers are summarized in Table 1 . The representative scanning electron microscope (SEM) images of the electrospun CD ( $\alpha-C D$ and $\beta-C D)$ nanofibers produced from different solution concentrations are depicted in Figs. 2 and 3. The electrospinning of CD solutions resulted in different average fiber diameters and morphologies depending on the $\mathrm{CD}$ type and $\mathrm{CD}$ solution concentrations.

We observed that the electrospinning of native CDs is quite similar to polymeric systems in which the solvent type, the solution concentration/viscosity, and the solution conductivity played a key role for the electrospinnability of CD nanofibers. That is, only the $\mathrm{CD}$ solutions having optimal concentration/viscosity and conductivity values were able to be electrospun into uniform nanofibers without any bead structure. In addition, we observed that the morphology and the diameter of the resulting electrospun nanofibers significantly vary with the type of CDs since the viscosity and conductivity of the solutions were different from each other. In our very recent studies, similar findings were also observed in the case of electrospinning of chemically modified CDs (HP $\beta C D, H P \gamma C D$, and $M \beta C D$ ) [27].

For $\alpha-C D$, vastly beaded structure along with very few nanofiber structures was obtained when $120 \%(w / v) \alpha$-CD solution was electrospun (Fig. 2a). The bead structures were gradually eliminated as the $\alpha$-CD concentration was increased from $120 \%$ through $140 \%$ $(\mathrm{w} / \mathrm{v})$ (Fig. 2b and c), and nanofibers having very few beads were obtained at $150 \%(w / v)$ concentration (Fig. 2d). Finally, bead-free and uniform $\alpha$-CD nanofibers (Fig. 2e) having fiber diameter in the range of $80-940 \mathrm{~nm}$ (Fig. $2 \mathrm{~g}$ ) with an average fiber diameter (AFD) of $375 \pm 150 \mathrm{~nm}$ were produced from the electrospinning of $160 \%(w / v) \alpha-C D$ solution. Likewise, we have also optimized the electrospinning of modified CDs (HP $\beta C D, H P \gamma C D$, and $M \beta C D$ ) in water at $160 \%(\mathrm{w} / \mathrm{v}) \mathrm{CD}$ concentration for obtaining bead-free nanofibers in our previously study [27].

The bead structures at lower concentrations were due to the low solution viscosity and the presence of inadequate amount of $\alpha$-CD aggregates, and therefore, mostly beads were formed instead of fully stretched fibers. This is because of the destabilization of the electrified jet during the electrospinning process. Bead-free nanofibers were obtained from $160 \%(w / v) \alpha-C D$, suggesting that this is the optimal concentration where the solution viscosity and the amount and the size of the CD aggregates were sufficient for the electrospinning of bead-free and uniform nanofiber. This finding is very similar to electrospinning of polymeric systems in which low concentration of polymer solution yielded beaded fiber structure due to the lack of polymer chain entanglements and overlapping, and mostly higher polymer concentrations are required for uniform fiber formation $[1,2,41]$. The rheology and DLS measurements (Figs. 4 and 5) indicated that as the concentration of $\alpha-C D$ increased from $120 \%$ through $160 \%(\mathrm{w} / \mathrm{v})$, the solution became more viscous and considerable amount of $C D$ aggregates was formed, and therefore, bead-free $\alpha-C D$ nanofibers were successfully obtained.

Similarly, the electrospinning of $\beta$-CD solutions at low concentration (120\% through $140 \%, w / v)$ yielded beaded nanofibers (Fig. 3a-c), but bead-free uniform $\beta-C D$ nanofibers were achieved from the electrospinning of $150 \%(w / v) \beta-C D$ solution (Fig. $3 d$ ). The nanofiber electrospun from $150 \%(w / v) \beta-C D$ solution has AFD of $220 \pm 90 \mathrm{~nm}$ and the fiber diameter was in the range of 90-460 nm (Fig. 3f).

In our previous study dealing with electrospinning of chemically modified CDs (HP $\beta C D, H P \gamma C D$, and $M \beta C D$ ) [27], we have shown that the morphologies and the diameters of the electrospun $\mathrm{CD}$ fibers were very much dependent on the $\mathrm{CD}$ type, $\mathrm{CD}$ concentration, and solvent type since the aggregation, viscosity, viscoelastic properties, and the solution conductivity were varied for each CD system. Here, it was also evident that electrospinning of native CDs was similar to chemically modified CDs where the fiber morphologies and the diameters were vary depending on the CD type and $\mathrm{CD}$ concentration. The optimal concentration for obtaining bead-free nanofibers was found as $160 \%$ and $150 \%$ for $\alpha$-CD and $\beta-C D$, respectively. As discussed in the later section, the rheological 

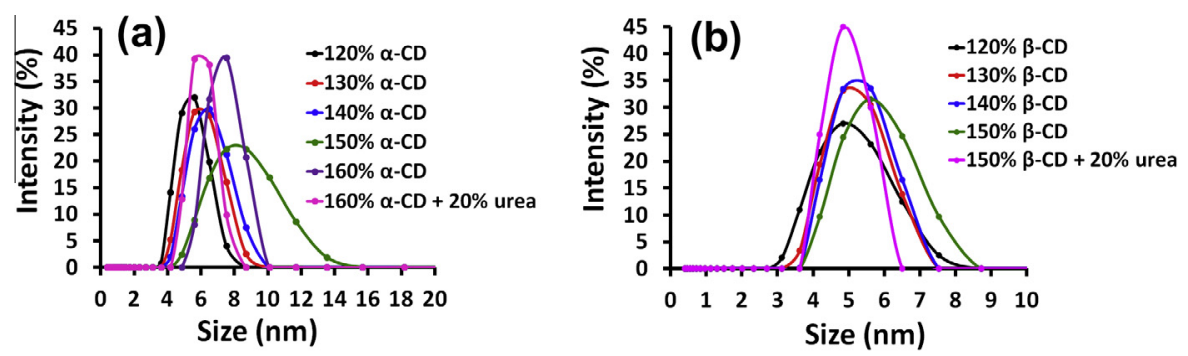

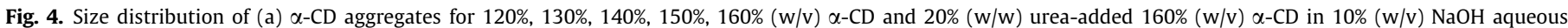
solution; (b) $120 \%, 130 \%, 140 \%, 150 \%(w / v) \beta-C D$, and $20 \%(w / w)$ urea-added $150 \%(w / v) ~ \beta-C D$ in $10 \%$ (w/v) NaOH aqueous solution.
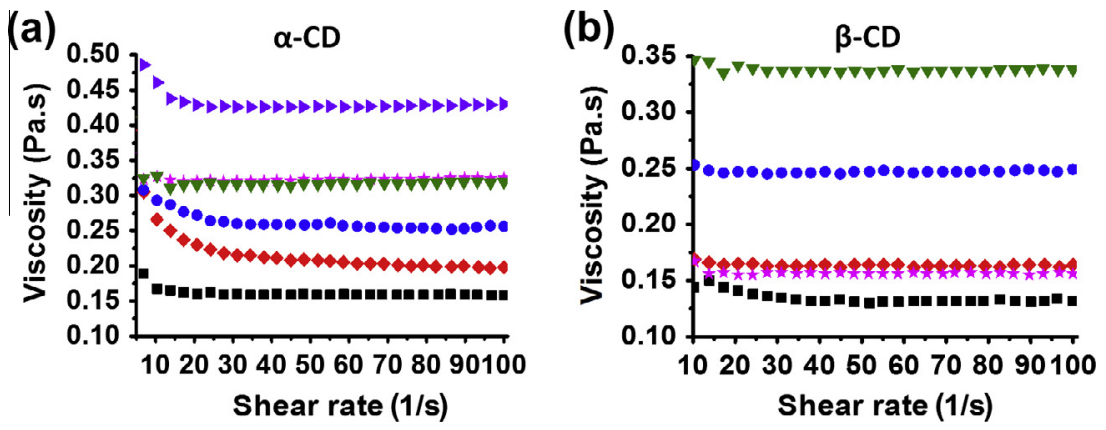

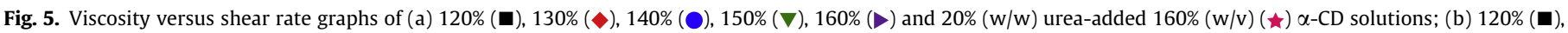
$130 \%(\bullet), 140 \%(\bullet), 150 \%(\nabla)$, and $20 \%(w / w)$ urea-added $150 \%(w / v)(\downarrow) \beta-C D$ solutions.

properties of the $\alpha$-CD and $\beta$-CD solutions were very similar, and therefore, fiber diameters close to each other were obtained, yet $\beta-C D$ nanofibers were somewhat thinner than the $\alpha$-CD nanofibers since $\beta-C D$ solution has lower concentration/viscosity and high conductivity values, and therefore, the electrified jet was subjected to more stretching during the electrospinning process $[1,2]$. These findings elucidated that electrospinning of CDs is quite similar to polymeric systems where the high solution concentration/viscosity is crucial for producing bead-free nanofibers from CDs.

The addition of urea reduces the intermolecular interaction between CD molecules by interrupting hydrogen bonding, and this resulted in disruption of self-association and aggregation of CDs in the solution $[42,43]$. The addition of urea $(20 \%(w / w)$ with respect to $C D$ ) to the optimized concentrations of CDs caused significant decrease in the viscosity and aggregate size (Table 1) since the urea breaks the hydrogen bonds among the $\mathrm{CD}$ molecules and disrupts the $C D$ aggregates; therefore, electrospinning of $C D$ solutions containing urea yielded beaded fibers or beads instead of uniform fibers (Figs. 2f and 3e).

\subsection{Cyclodextrin aggregation in solutions}

The DLS measurements were performed in order to investigate the aggregation of CDs in their highly concentrated solutions. The size distribution of CD aggregates measured by DLS for $\alpha-C D$ and $\beta-C D$ solutions is given in Fig. 4 , and the data are summarized in Table 1 . The DLS measurements elucidated the presence of selfaggregated $\alpha$-CD molecules in their concentrated solutions (Fig. 4a and Table 1 ). The size of the $\alpha$-CD aggregates increased from $5.5 \mathrm{~nm}$ to $8.29 \mathrm{~nm}$ as the concentration was increased from $120 \%$ to $160 \%(\mathrm{w} / \mathrm{v})$. The size of the aggregates decreased from $8.29 \mathrm{~nm}$ to $6.04 \mathrm{~nm}$ for the urea-added $160 \%(\mathrm{w} / \mathrm{v}) \alpha$-CD solution confirming the depletion of the $\alpha-C D$ aggregates with the addition of urea. In the case of $\beta-C D$, the aggregate size was increased from $4.98 \mathrm{~nm}$ to $5.96 \mathrm{~nm}$ as the $\beta-C D$ concentration was increased from $120 \%$ to $150 \%(\mathrm{w} / \mathrm{v}$ ) (Table 1$)$. The size of the $\alpha$-CD aggregates was slightly bigger than the size of the $\beta$-CD aggregates in the same solution concentration. The DLS and viscosity data are in good agreement with each other, and slight higher viscosity values were recorded for $\alpha$-CD solutions when compared to $\beta-C D$ solutions owing to the higher amount of $C D$ aggregates and their growing sizes as the concentration of the $C D$ increased in the solution. In brief, the DLS measurements confirmed that the CD molecules form substantial amount of aggregates in their high concentrations, and this resulted in full stretching of electrified jet yielding bead-free uniform fiber formation without using any polymeric carrier.

\subsection{Rheology of cyclodextrin solutions}

The rheological properties of $\mathrm{CD}$ solutions were examined by performing shear rate sweep viscosity and frequency sweep oscillation tests. Both of these tests were run for CD solutions having $120 \%(\mathrm{w} / \mathrm{v})$ concentration up to the optimal concentration level (160\% and $150 \%(w / v)$ for $\alpha-C D$ and $\beta-C D$, respectively) in which the bead-free nanofibers were obtained. The viscosity of $C D$ solutions as a function of shear rate was displayed in Fig. 5. It was observed that the viscosity of $C D$ solution for the same concentration was being independent of shear rate indicating that the CD systems show characteristic of a Newtonian fluid. In addition, the solution viscosity of CDs increases with the increasing CD concentration due to the presence of higher number of aggregates and their growing sizes (see Table 1 and Fig. 4). While the viscosity of $120 \%(w / v) \alpha-C D$ solution was measured as 0.16 Pa s, it reached to $0.43 \mathrm{~Pa}$ s for the $160 \%(\mathrm{w} / \mathrm{v}) \alpha-\mathrm{CD}$. The viscosity of $\beta-\mathrm{CD}$ solution was increased from $0.13 \mathrm{~Pa} \mathrm{~s}(120 \%, \mathrm{w} / \mathrm{v})$ to $0.33 \mathrm{~Pa} \mathrm{~s}(150 \%, \mathrm{w} / \mathrm{v})$. As mentioned previously, the addition of urea reduces hydrogen bonding between $\mathrm{CD}$ molecules and therefore disturbs the $\mathrm{CD}$ aggregation $[42,43]$. Here, the addition of $20 \%$ (w/w) urea (with respect to $C D$ ) to the optimized concentrations of CDs caused significant decline in their viscosity levels. The viscosity of the $C D$ solutions was decreased from $0.43 \mathrm{~Pa} \mathrm{~s}$ to $0.33 \mathrm{~Pa} \mathrm{~s}$ and $0.33 \mathrm{~Pa} \mathrm{~s}$ to $0.15 \mathrm{~Pa}$ s for $\alpha-C D$ and $\beta-C D$, respectively. Similarly, the size of 

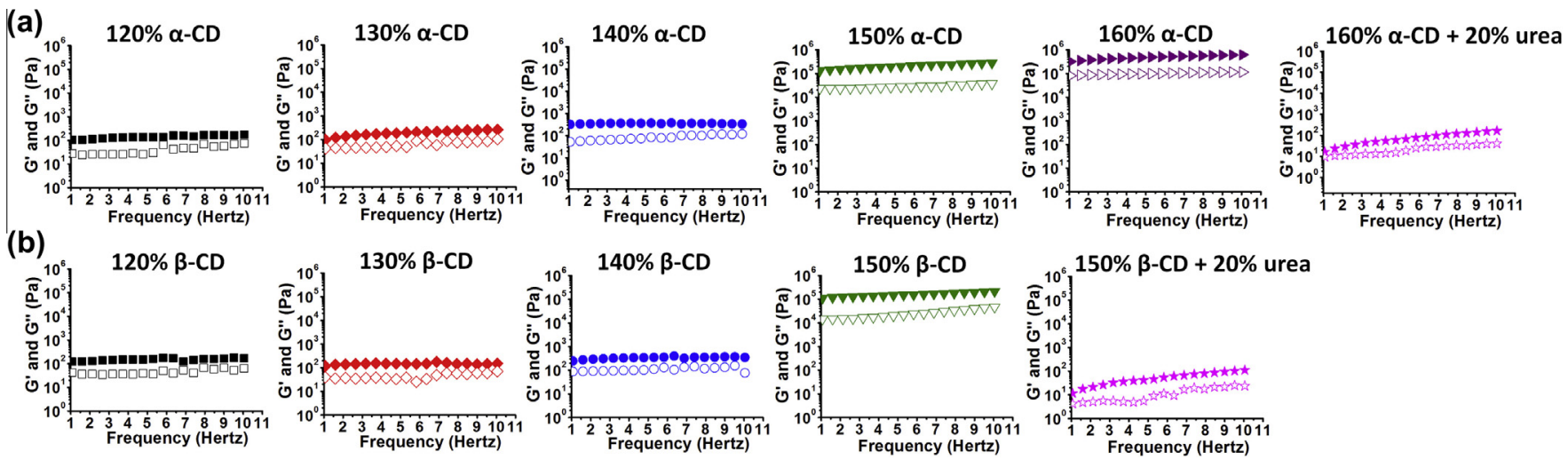

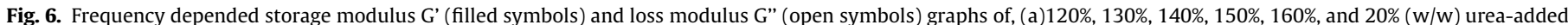
$160 \%(w / v) \alpha$-CD solutions; (b) $120 \%, 130 \%, 140 \%, 150 \%$, and $20 \%(w / w)$ urea-added $150 \%(w / v) \beta-C D$ solutions.

the CD aggregates measured by DLS was decreased from $8.29 \mathrm{~nm}$ to $6.04 \mathrm{~nm}$ and $5.96 \mathrm{~nm}$ to $4.91 \mathrm{~nm}$ for $\alpha-C D$ and $\beta-C D$ solutions containing urea, respectively. SEM images (Figs. $2 \mathrm{f}$ and $3 \mathrm{e}$ ) clearly showed that the electrospinnability of CD solutions was significantly affected with the addition of urea. Beads along with few fiber structures were obtained from the electrospinning of ureacontaining $\alpha-C D$ and $\beta-C D$ solutions (Figs. 2 f and $3 e$ ). It was also worth mentioning that the electrospinning of fibers from urea-containing $C D$ solutions became much difficult since the jet breakup observed very frequently and much less fibers were deposited on the collector.

The viscoelastic properties of the $\mathrm{CD}$ solutions were studied by the frequency sweep oscillation measurements. Fig. 6 shows the storage and loss modulus of $\mathrm{CD}$ solutions as a function of frequency. For all $\mathrm{CD}$ solutions at given concentration, the storage modulus was higher than that of the loss modulus in the whole frequency range indicating that these highly concentrated $C D$ solutions behave as a viscoelastic solid [44]. At a fixed CD concentration, both storage and loss modulus were steady under the applied frequency range, but increasing the concentration of CD solutions resulted in higher storage and loss modulus values. We have observed no crossover point between storage and loss modulus. In addition, the storage modulus was always higher than the loss modulus elucidated that $\mathrm{CD}$ solutions show predominantly solid-like behavior for CD systems in all studied concentrations. Moreover, at higher $\mathrm{CD}$ concentrations, the gap between storage and loss modulus became larger. This is mostly because the solid-like part becomes more pronounced as the concentration increases due to the increasing aggregation. Fig. $6 a$ and $b$ also indicates that the viscoelastic properties of $\alpha-C D$ and $\beta-C D$ solutions are almost same with the similar modulus value for the same concentration. The oscillation tests were also applied to ureaadded CD solutions, and the significant decrease for the modulus values was observed for the optimized concentrations of both $C D$ types. As mentioned before, the addition of urea disturbs the hydrogen bonding among the $C D$ molecules, so the size of the aggregates get smaller which results in solid density depression in the solution that supplies the elastic property. The modulus of urea-added $160 \%(\mathrm{w} / \mathrm{v}) \alpha-\mathrm{CD}$ and $150 \%(\mathrm{w} / \mathrm{v}) \beta$-CD solutions was decreased significantly and reached to the modulus value similar to their $120 \%(\mathrm{w} / \mathrm{v})$ concentration level. As expected, the electrospinning of the urea-added $160 \%(w / v) \alpha-C D$ and $150 \%(w / v) \beta-C D$ solutions resulted in similar fiber morphologies when compared to their $120 \%(\mathrm{w} / \mathrm{v})$ solutions. In brief, the electrospinning of the urea-added CD solution did not result in uniform and bead-free nanofiber formation simply because of the break up of the electrified jet due to the presence of insufficient $C D$ aggregates (Figs. $2 \mathrm{f}$ and 3e). Therefore, it is evident that the presence of substantial amount of $\mathrm{CD}$ aggregates via hydrogen bonding plays a key role for the electrospinning of uniform and bead-free nanofibers from CD solutions.

\subsection{Structural characterization of the electrospun $C D$ nanofibers}

The $\alpha-C D$ and $\beta-C D$ are crystalline material having crystal structures referred to as cage or channel type [34]. In the cage-type packing, the $C D$ molecules are in arrangement in which the cavity of each $\mathrm{CD}$ molecule is blocked by neighboring molecules. In the case of channel-type packing, the CD molecules are aligned and stacked on top of each other forming long cylindrical channels, and this channel-type packing is commonly observed when CDs form inclusion complexes with guest molecules [34]. Here, we have performed the structural analyses of CD nanofibers by XRD. The asreceived $\alpha-C D$ and $\beta-C D$ in powder form are crystalline having a cage-type packing [34]. However, the XRD data of electrospun $\alpha$ $\mathrm{CD}$ and $\beta-C D$ nanofibers showed that the diffraction peaks were absent and only halo XRD pattern was observed indicating that these CD nanofibers have amorphous structure without any particular crystal formation (Fig. 7). The HR-TEM further proved that CD molecules were randomly distributed without showing any presence of particular orientation or crystalline aggregation in the fibers (Fig. 8). It is likely that CD molecules could not pack into crystal structure because of the rapid evaporation of solvent along with the very fast and continuous stretching of the jet during the electrospinning process. We have also performed the XRD study for these $C D$ nanofibers after 1 year of their production, and we observed that the amorphous structure was protected for $\alpha-C D$ and

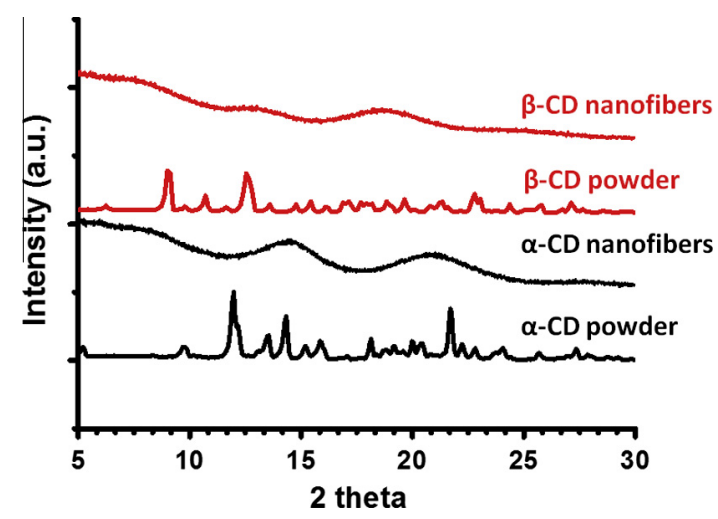

Fig. 7. XRD patterns of as-received $\alpha-C D$ and $\beta-C D$ powders and, $\alpha-C D$ and $\beta-C D$ nanofibers. 


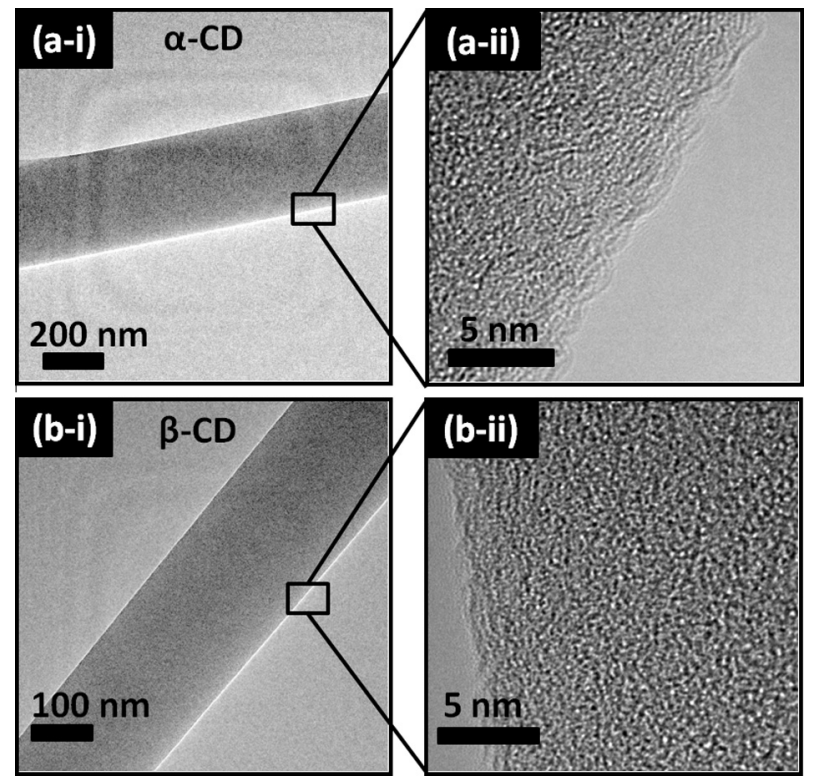

Fig. 8. TEM and HR-TEM images of electrospun (a-i, ii) $\alpha-C D$ and (b-i, ii) $\beta-C D$ nanofiber.

$\beta$-CD nanofibers, and no transformation to cage-type packing occurred which is the most stable crystalline form for native CDs [34].

\section{Conclusions}

We have successfully produced nanofibers from native CDs of $\alpha-C D$ and $\beta-C D$ via electrospinning technique without using any carrier polymeric matrix. At lower CD concentrations, beaded nanofibers were obtained, but, as the $C D$ concentrations were increased, the transformation from beaded to bead-free nanofibers was observed. The optimal concentrations for producing bead-free nanofibers were $160 \%$ and $150 \%(w / v)$ for $\alpha-C D$ and $\beta-C D$, respectively. The DLS and rheology measurements indicated the presence of self-associated $C D$ aggregates in the solutions. It was found that the high solution viscosity and viscoelastic solid-like behavior of CD solutions played a key role for the electrospinning of bead-free nanofibers from these two native $C D$ types. The size of $C D$ aggregates got smaller, and the viscosity of the $\mathrm{CD}$ solutions decreased significantly with the addition of urea. This situation affected the electrospinnability of CD solutions and beaded fibers and/or beads were obtained. The XRD and HR-TEM studies revealed that electrospun $C D$ nanofibers were in amorphous state.

CDs are naturally occurring non-toxic cyclic oligosaccharides having host-guest inclusion complexation capability with other molecules. So, electrospinning of CD nanofibers would have unique properties by combining the very large surface area of nanofibers with specific functionality of the $\mathrm{CD}$. For instance, native $\mathrm{CDs}$ have different cavity size which can allow selective inclusion complexation with various molecules of different sizes. In addition, CDs are already being used in various fields including pharmaceutical, food, textiles, biotechnology, and filtration/separation systems. Hence,
CDs in the form of nanofibrous web may extend the use of CDs in the aforementioned areas.

\section{Acknowledgments}

State Planning Organization (DPT) of Turkey is acknowledged for the support of UNAM-Institute of Materials Science \& Nanotechnology. T. Uyar acknowledges EU FP7-PEOPLE-2009-RG Marie Curie-IRG for funding NANOWEB (PIRG06-GA-2009-256428) project. A. Celebioglu acknowledges TUBITAK-BIDEB for the national PhD study scholarship.

\section{References}

[1] S. Ramakrishna, K. Fujihara, W. Teo, T. Lim, Z. Ma, An Introduction to Electrospinning and Nanofibers, World Scientific Publishing Company, 2005.

[2] J.H. Wendorff, S. Agarwal, A. Greiner, Electrospinning: Materials, Processing, and Applications, Wiley-VCH, Germany, 2012.

[3] S. Agarwal, J.H. Wendorff, A. Greiner, Macromol. Rapid. Commun. 31 (2010) 1317.

[4] A. Greiner, J.H. Wendorff, Angew. Chem. Int. Ed. 46 (2007) 5670.

[5] S. Agarwal, A. Greiner, Polym. Adv. Technol. 22 (2011) 372.

[6] S. Zhan, D. Chen, X. Jiao, S. Liu, J. Colloid Interface Sci. 308 (2007) 265

[7] C. Shin, J. Colloid Interface Sci. 302 (2006) 267.

[8] X. Li, M. Cao, H. Zhang, L. Zhou, S. Cheng, J. Colloid Interface Sci. 382 (2012) 28.

[9] C. Su, C. Shao, Y. Liu, J. Colloid Interface Sci. 359 (2011) 220.

[10] S. Ramakrishna, R. Jose, P. Archana, A. Nair, R. Balamurugan, J. Venugopal, W. Teo, J. Mater. Sci. 45 (2010) 6283.

[11] S. Agarwal, A. Greiner, J.H. Wendorff, Adv. Funct. Mater. 19 (2009) 2863

[12] J. Xie, X. Li, Y. Xia, Macromol. Rapid Commun. 29 (2008) 1775.

[13] R. Rahul, S. Kumar, R. Sridhar, J. Sundaramurthy, V.J. Reddy, S. Ramakrishna, J. Mater. Chem. 22 (2012) 12953.

[14] V. Thavasi, G. Singh, S. Ramakrishna, Energy Environ. Sci. 1 (2008) 205.

[15] K. Yoon, B.S. Hsiao, B. Chu, J. Mater. Chem. 18 (2008) 5326.

[16] M.G. McKee, G.L. Wilkes, R.H. Colby, T.E. Long, Macromolecules 37 (2004) 1760.

[17] P. Gupta, C. Elkins, T.E. Long, G.L. Wilkes, Polymer 46 (2005) 4799.

[18] S.L. Shenoy, W.D. Bates, H.L. Frisch, G.E. Wnek, Polymer 46 (2005) 3372.

[19] J.H. Yu, S.V. Fridrikh, G.C. Rutledge, Polymer 47 (2006) 4789.

[20] S. Talwar, A.S. Krishnan, J.P. Hinestroza, B. Pourdeyhimi, S.A. Khan, Macromolecules 43 (2010) 7650.

[21] M.G. McKee, J.M. Layman, M.P. Cashion, T.E. Long, Science 311 (2006) 353.

[22] G. Singh, A.M. Bittner, S. Loscher, N. Malinowski, K. Kern, Adv. Mater. 20 (2008) 2332.

[23] M.P. Cashion, X. Li, Y. Geng, M.T. Hunley, T.E. Long, Langmuir 26 (2010) 678.

[24] X. Yan, M. Zhou, J. Chen, X. Chi, S. Dong, M. Zhang, X. Ding, Y. Yu, S. Shaod, F. Huang, Chem. Commun. 47 (2011) 7086.

[25] A. Celebioglu, T. Uyar, Chem. Commun. 46 (2010) 6903.

[26] A. Celebioglu, T. Uyar, Langmuir 27 (2011) 6218.

[27] A. Celebioglu, T. Uyar, Nanoscale 4 (2012) 621.

[28] J.L. Manasco, C.D. Saquing, C. Tang, S.A. Khan, RSC Adv. 2 (2012) 3778

[29] W. Zhang, M. Chen, B. Zha, G. Diao, Phys. Chem. Chem. Phys. 14 (2012) 9729.

[30] J.C. Singer, R. Giesa, H.W. Schmidt, Soft Matter 8 (2012) 9972.

[31] J. Szejtli, Chem. Rev. 98 (1998) 1743.

[32] A.R. Hedges, Chem. Rev. 98 (1998) 2035.

[33] L.X. Song, L. Bai, X.M. Xu, J. He, S.Z. Pan, Chem. Rev. 253 (2009) 1276.

[34] W. Saenger, J. Jacob, K. Gessler, T. Steiner, D. Hoffmann, H. Sanbe, K. Koizumi, S.M. Smith, T. Takaha, Chem. Rev. 98 (1998) 1787.

[35] Í.X. García-Zubiri, G. González-Gaitano, J.R. Isasi, J. Colloid Interface Sci. 307 (2007) 64.

[36] H.M.C. Marques, Flavour Frag. J. 25 (2010) 313.

[37] N. Morin-Crini, G. Crini, Prog. Polym. Sci. 38 (2013) 344.

[38] M. Messner, S. Kurkov, P. Jansook, T. Loftsson, Int. J. Pharm. 387 (2010) 199.

[39] M. Bonini, S. Rossi, G. Karlsson, M. Almgren, P. Nostro, P. Baglioni, Langmuir 22 (2006) 1478.

[40] J. Szejtli, J. Mater. Chem. 7 (1997) 575.

[41] T. Uyar, F. Besenbacher, Polymer 49 (2008) 5336

[42] L. Szente, J. Szejtli, G. Kis, J. Pharm. Sci. 87 (1998) 778.

[43] W. Hinze, D. Pharr, Z. Fu, W. Burkert, Anal. Chem. 61 (1989) 422.

[44] O. Jazkewitsch, H. Ritter, Macromolecules 44 (2011) 375. 